\title{
Mode-Switch Strategy for Dual-Motor Coupling System of Electric Vehicles Based on Optimal Dynamic Performance
}

\author{
S.M. Han, X.F. Yin, X.H. Wu \\ Sichuan Provincial Key Laboratory of Automotive Engineering \\ Xihua University \\ Chengdu, China
}

\begin{abstract}
To improve the accelerating ability of electric vehicle, a mode-switch control strategy based on optimal dynamic performance for the dual-motor coupling system (DMCS) is put forward in this investigation. The configuration and work modes of the investigated DMCS system have been discussed at first, and then the acceleration is treated as the objective for modeswitch strategy optimization for DMCS of electric vehicle. And a simulation model has been developed using MATLAB/Simulink to evaluate. The results show that the proposed control strategy can improve the dynamic performance of the electric vehicle equipped with DMCS system.
\end{abstract}

Keywords-electric vehicle; dual-motor; coupling; power train; dynamic performance; mode-switch

\section{INTRODUCTION}

Mode-switch control strategy of dual-motor coupling system (DMCS) is one of the key technologies for hybrid drive system to achieve maximum accelerating ability and get maximum driving force for electric vehicles. In this paper, two parameters, pedal position and speed of vehicle are chosen as the mode-switch control parameters, based on the structure characteristics of the investigated DMCS system and related control strategies of hybrid drive system. And the parameters suitable for the dual-motor and the coupler of the DMCS system has been determined according to the parameter matching principle of power train system of electric vehicles. Furthermore, the mode-switch control strategy based on optimal dynamic performance has been discussed in details. Finally the proposed control strategy has been evaluated via simulations.

\section{DMCS SYSTEM}

\section{A. Configuration and Work Principle}

The investigated DMCS system consists of two motors (M1, M2), a set of planetary gear mechanism and two locking mechanism (B1, B2). The sun gear of planetary gear mechanism is connected to the rotor of motor 1 , the locking mechanism B1 is fixed on the driver shaft of sun gear, which is used to brake the sun gear. The side of ring gear is connected to the rotor of motor 2 , and the locking mechanism B2 is fixed on the other side of ring gear, which is used to brake the ring gear. The planetary carrier is connected to the final drive and the latter transfers the power to the tires. The structure diagram of the DMCS is shown as Fig 1.

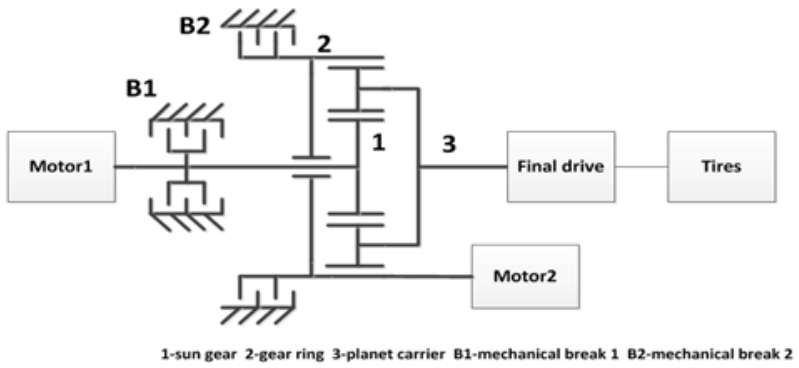

FIGURE I. THE STRUCTURE DIAGRAM OF DMCS

\section{B. Work Modes Classification}

This DMCS have three work modes [1] through controlling of the motor1, motor2 and the locking mechanism $\mathrm{B} 1$ and $\mathrm{B} 2$.

1) Mode 1 (single motor 1 drive): In this mode, the locking mechanism B2 is working and braking the ring gear, the motor 2 is not working. The locking mechanism B1 is in off status. The power transferring route is from motor 1 to the sun gear, and the sun gear transmit powers to the planetary gear, and then to the planetary carrier.

2) Mode 2(single motor 1 drive): In this mode, the motor 2 is stopping work, the locking mechanism B1 is working and braking the sun gear. Then, the locking mechanism B2 is in off status. The power transferring route is from motor 2 to the ring gear, and then to the planetary carrier.

3) Mode 3 (dual-motor speed coupling drive): In this mode, the locking mechanism B1and B2 are in off status, while motor 1 and motor 2 are working. The power transferring route is from motor 1 to the sun gear and from motor 2 to the ring gear at the same time, and then merged to the planetary carrier. The modes classification of DMCS are shown in Table 1

TABLEI. WORK MODES

\begin{tabular}{|c|c|c|c|c|}
\hline Modes & M1 & M2 & B1 & B2 \\
\hline Mode 1 & work & stop & off & on \\
\hline Mode 2 & stop & work & on & off \\
\hline Mode 3 & work & work & off & off \\
\hline
\end{tabular}


III. MODE-SWITCH CONTROL STRATEGY BASED ON OPTIMAL DYNAMIC PERFORMANCE

The basic parameter and performance indices of the prototype vehicle are shown as Table 2.

TABLEII. VEHICLE PARAMETER ANd IndicAtor PERFormance

\begin{tabular}{|l|l|}
\hline Vehicle parameters and performance demand & values \\
\hline Vehicle mass $m(\mathrm{~kg})$ & 1700 \\
\hline Tires radius $r(\mathrm{~m})$ & 0.334 \\
\hline Rolling resistance $f$ & 0.014 \\
\hline Aerodynamic drag $C_{d}$ & 0.4 \\
\hline Frontal area $A\left(\mathrm{~m}^{2}\right)$ & 2 \\
\hline The top speed $u_{\text {max }}(\mathrm{km} / \mathrm{h})$ & 150 \\
\hline The maximum gradability & $30 \%$ \\
\hline The acceleration time of $0-100 \mathrm{~km} / \mathrm{h}$ & 16.5 \\
\hline
\end{tabular}

According the method of parameter matching [2], the result of parameter as following.

TABLEIII. The PARAMETER Result OF DMCS

\begin{tabular}{|c|c|c|}
\hline Components & Parameters & Values \\
\hline \multirow{2}{*}{ Motor 1 } & Rated / peak power $(\mathrm{kW})$ & $30 / 60$ \\
\cline { 2 - 3 } & Rated / peak speed $(\mathrm{rpm})$ & $3000 / 6000$ \\
\hline \multirow{2}{*}{ Motor 2 } & Rated / peak power $(\mathrm{kW})$ & $25 / 50$ \\
\cline { 2 - 3 } & Rated / peak speed $(\mathrm{rpm})$ & $3000 / 6000$ \\
\hline \multirow{2}{*}{ Coupler } & The character parameter $k$ & 3.5 \\
\cline { 2 - 3 } & The entire transmission ratio $\boldsymbol{i}$ & 4.5 \\
\hline
\end{tabular}

According to the parameter matching result, the driving force-speed diagram of DMCS under three work modes can be drawn as Fig.2.

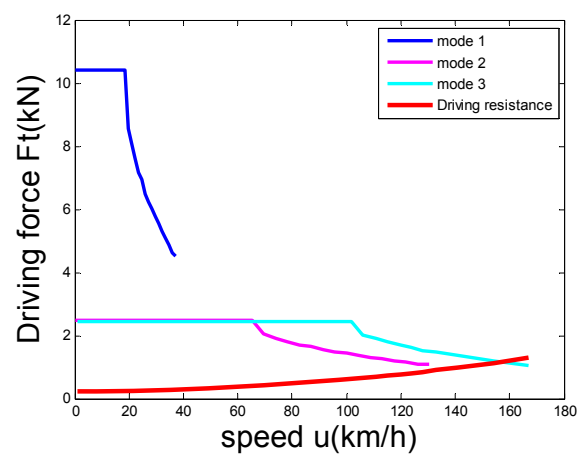

FIGURE II. THE DRIVING FORCE-SPEED DIAGRAM OF DMCS

According to the knowledge of vehicle theory, the acceleration time can reflect the vehicle dynamic performance to a certain extend, therefore acceleration has been used to evaluate the vehicle dynamic performance when the car driving on the road[2].

The acceleration of electric vehicles can be calculated by $\frac{d u_{a}}{d_{t}}=\frac{1}{\delta m}\left(\frac{T_{o} \cdot i}{r}-m g f-\frac{C_{d} \cdot A \cdot u_{a}{ }^{2}}{21.15}\right)$

Where , $\frac{d u_{a}}{d_{t}}$ is the acceleration $\left(\mathrm{m} / \mathrm{s}^{2}\right), T_{o}$ is the output torque of planetary gear coupler, $u_{a}$ is the vehicle speed $(\mathrm{km} / \mathrm{h})$.

According to the structure of DMCS, draw the curve of 'acceleration-speed' under the different pedal position and different work modes. Fig.3 and Fig.4 are show that a curve of 'acceleration- speed' when the pedal position is $100 \%$, $80 \%$ and $60 \%$.

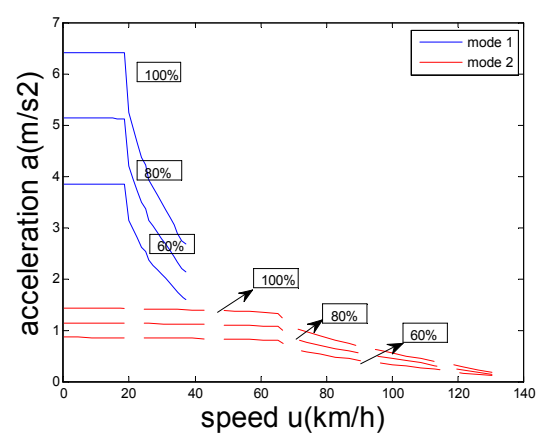

FIGURE III. THE ACCELERATION-SPEED CURVE OF MODE 1 AND MODE 2

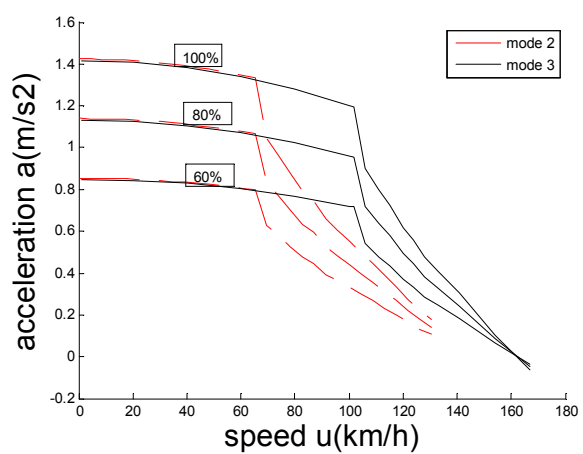

FIGURE IV. THE ACCELERATION-SPEED CURVE OF MODE 2 AND MODE 3

Fig. 3 and Fig. 4 are show that in order to obtain the great power performance and reduce the acceleration time of $0-100$ $\mathrm{km} / \mathrm{h}$, electric vehicles needs to travel with the greatest acceleration at different work modes. According to the curve of acceleration, we can formulate the switch speed among different modes at the same pedal position, the switch speed is defined as the point of increasing speed. Finally, we can formulate deceleration point in accordance with the point of increasing speed. According to the principle of modes switching, deceleration point must below the point of increasing speed so that to avoid this situation of frequent switching occurs, so that setting a certain speed difference between increase speed point and deceleration point. Referring to the method of automatic transmission shift schedule [1], the combined shift schedule is selected as the modes switching 
control law of DMCS between mode 1 and mode 2. The reason is that when the pedal position is larger (usually more than 60 percent), the driver hope the car have better dynamic performance probability. As the acceleration of mode 1 is larger than mode 2 , mode 2 should be switched to the mode 1 more early during the process of deceleration. Therefore, when the pedal position is larger than 60 percent, we choose the style of equivalent-delay as the modes switching law between mode 1 and mode 2 . When the pedal position is less than 60 percent, the driver hope the car have better economic performance probability. In order to saving the energy, and compare three modes of DMCS, we find that mode 2 have a minimum motor power demand and energy consumption is lower than others, so electric vehicles should be working in mode 2 . Therefore, during the process of deceleration, mode 2 should be switched to the mode 1 more late, we chosen the style of convergent as the modes switching law between mode1 and mode 2. Considering the mode 2 energy consumption is lower and the acceleration of mode 2 is equal to mode 3 , we select the style of equivalent-delay as modes switching law between mode 2 and mode 3 when the pedal position from 100 percent to 10 percent. Modes switching curve of DMCS based on the optimal dynamic performance is shown as Fig.5.

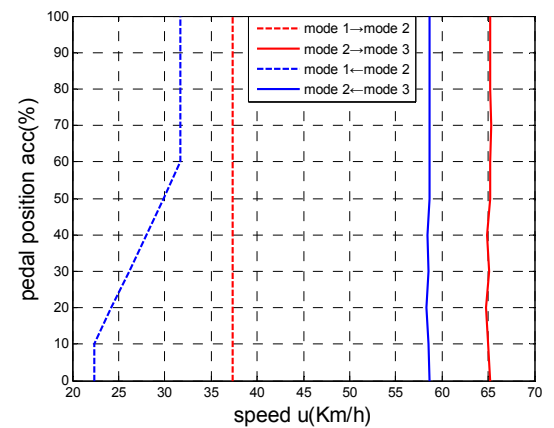

FIGURE V. MODES SWITCHING CURVE OF DMCS BASED ON THE OPTIMAL DYNAMIC PERFORMANCE

Finally, according to the modes switching control law based on the optimal dynamic performance and the structure of DMCS, we formulate the mode-switch control strategy of DMCS[3]. The entire control process of mode-switch is shown as Fig.6.

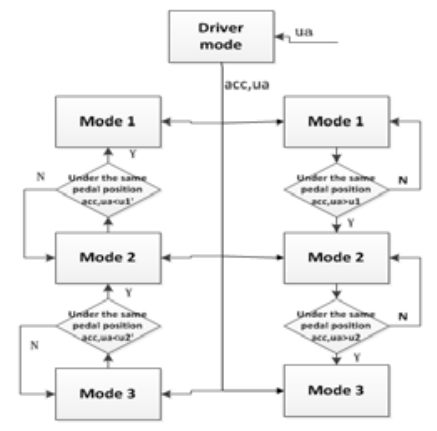

FIGURE VI. THE ENTIRE CONTROL PROCESS OF MODE-SWITCH
In the Fig.6, $a c c$ is the pedal position, ${ }^{u_{a}}$ is the vehicle speed, $u_{1}$ is the acceleration speed of mode 1 switching to the mode 2 and $u_{2}$ is the acceleration speed of mode 2 switching to the mode $3 . u_{1}^{\prime}$ is the deceleration speed of mode 2 switching to the mode 1 and $u_{2}^{\prime}$ is the deceleration speed of mode 3 switching to the mode 2 .

\section{SimUlATION}

\section{A. Simulation Model}

Matlab/Simulink have been used to build the electric vehicle simulation model. This model includes motor model, the planetary gear mechanism model, vehicle model, working mode control model and the driver model. Power transmission system simulation model is shown as Fig.7

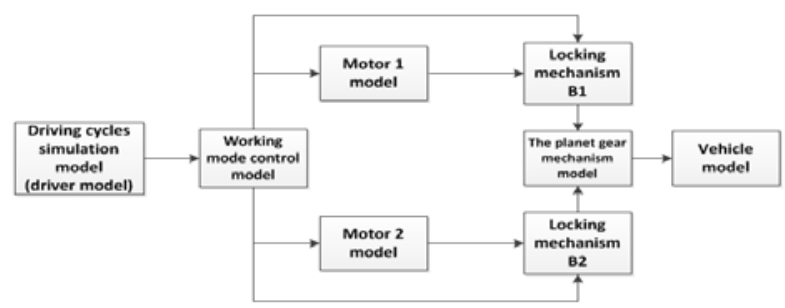

FIGURE VII. POWER TRANSMISSION SYSTEM SIMULATION MODEL

\section{B. Simulation Results}

In order to verify whether the mode-switch strategy is reasonable, the acceleration processes under $100 \%$ and $90 \%$ pedal position are simulated and the results are shown in Fig. 8 and Fig. 9 respectively. The acceleration time from 0 $100 \mathrm{~km} / \mathrm{h}$ corresponding to $100 \%$ and $90 \%$ pedal position, are $13.61 \mathrm{~s}$ and $16.06 \mathrm{~s}$ respectively.

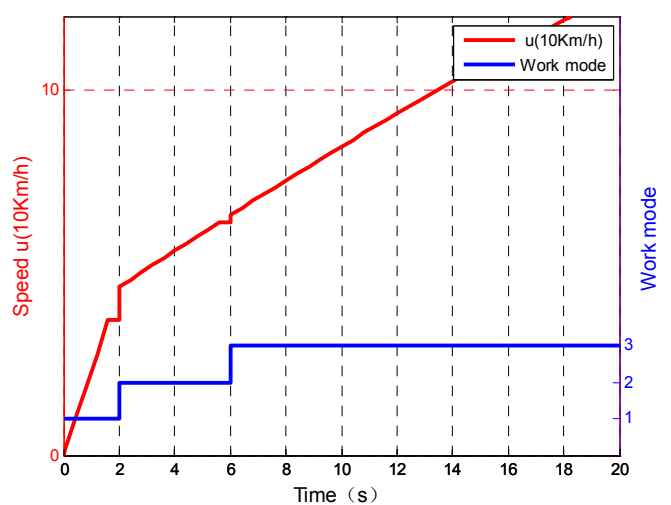

FIGURE VIII. ACCELERATION PROCESSES UNDER100\% PEDAL POSITION 


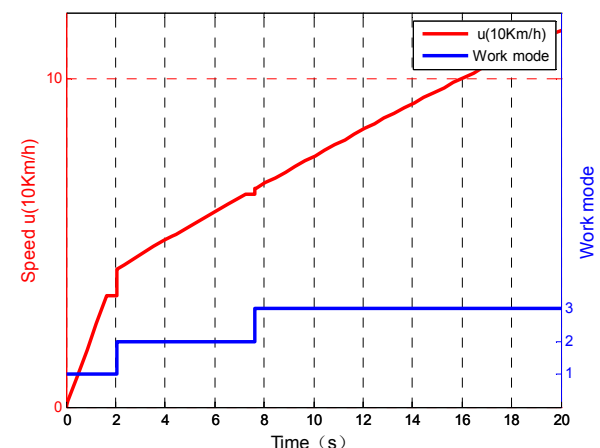

FIGURE IX. ACCELERATION PROCESSES UNDER 90\% PEDAL POSITION

\section{CONCLUSION}

A mode-switch control strategy based on optimal dynamic performance for DMCS system is proposed and has been verified via simulation. The simulation results show that the proposed control strategy is effective and can improve the power performance of the electric vehicle.

\section{ACKNOWLEDGMENTS}

The work was supported in part by Science \& Technology Department of Sichuan Province (Grant No. 2015TD0021), the Basic and Applied Research Project of Sichuan Province (Grant No. 2013JY0088), and Innovation Fund for Graduate Students at Xihua University (Grant No.ycjj2014156)

\section{REFERENCES}

[1] Sun, D., and Chen, Z., Parameter Matching and Design of Dual-drive Electric Vehicle Transmission System under NEDC working conditions, Journal of Internal Combustion Engines, August. 2013.

[2] Wang, Z, and Zhang, C., The eletric drive theory and design of EV, Machinery Industry Press: Beijing, China.

[3] Hu, M., Zeng, J., Xu, S., Fu, C., Efficiency study of a Dual-motor coupling EV Powertrain, IEEE Transaction on Vehicle Technology, 2014(9) 